\title{
Infeç̧ão experimental de embriões de frango de corte com Salmonella enterica sorovar Enteritidis fagotipo 4
}

[Experimental infection of broiler embryos with Salmonella enterica sorovar Enteritidis phagotype 4]

\author{
M.A. Andrade ${ }^{1}$, A.J. Mesquita ${ }^{1,3}$, J.H. Stringhini ${ }^{1,3^{*}}$, A.A. Pedroso ${ }^{1}$, N.S.M. Leandro ${ }^{1,3}$, \\ M.B. Café $e^{1}$ M.S. Mattos ${ }^{2}$ \\ ${ }^{1}$ Escola de Veterinária - UFG \\ Caixa Postal 131 \\ 74001-970 - Goiânia, GO \\ ${ }^{2}$ Aluna de pós-graduação - EV-UFG - Goiânia, GO \\ ${ }^{3}$ Bolsista do $\mathrm{CNPq}$
}

\section{RESUMO}

Avaliou-se a infecção experimental por Salmonella Enteritidis fagotipo 4 (SEpt4) em embriões de frango de corte para averiguar a habilidade de penetração através da casca e o efeito da inoculação no albúmen, considerando-se a mortalidade, a eclodibilidade e a colonização intestinal dos pintos eclodidos. Foram realizados dois experimentos, distribuídos em quatro tratamentos (T) cada, com 200 e 194 ovos incubáveis das linhagens Ross e ISA Label, respectivamente. Utilizaram-se ovos não sanitizados e inoculados na casca com Salmonella Enteritidis (T1) ou com placebo (T2); ou inoculados no albúmen com Salmonella Enteritidis (T3) ou com placebo (T4). Imediatamente após a inoculação, os ovos foram incubados, e a mortalidade embrionária avaliada após 96, 432 e 528 horas. Salmonella Enteritidis inoculada na casca manteve-se viável na casca e nas membranas durante todo o período de incubação e migrou para o interior dos ovos, entretanto não afetou os parâmetros de incubação. O patógeno inoculado no albúmen determinou mortalidade embrionária tardia nas linhagens Ross, 17,0\%, e ISA Label, 13,0\%, e originou pintos com maior freqüência de colonização intestinal por Salmonella Enteritidis, 76,7\% e $26,7 \%$ para Ross e ISA Label, respectivamente.

Palavras-chave: frango de corte, Salmonella Enteritidis, infecção, casca, albúmen, transmissão vertical

\begin{abstract}
The experimental infection of Salmonella Enteritidis phagotype 4 (SEpt4) was evaluated in broilers embryos to verify the ability of penetration through eggshell and the effect of albumen inoculation considering embryo mortality, hatchability, and intestinal colonization of hatched chicks. Two trials were conducted using in four treatments each, totaling 200 and 194 fertile eggs of Ross and ISA Label lineages, respectively. Non-sanitized eggs were inoculated on the shell with Salmonella Enteritidis (Treatment 1) or placebo (Treatment 2); and eggs were inoculated in albumen with Salmonella Enteritidis (Treatment 3) or placebo (Treatment 4). Immediately after inoculation, the eggs were incubated and embryo mortality was evaluated after 96, 432, and 528 hours. The results showed that Salmonella Enteritidis inoculated on egg shell remained active there and in shell membranes during all incubation period and migrated to the interior of the eggs; however, it did not affect the incubation parameters. It was observed that Salmonella Enteritidis inoculated in albumen caused late embryo mortality in Ross (17.0\%) and ISA Label (13.0\%) lineages, and originated chicks with high frequency of intestinal colonization by Salmonella Enteritidis, being 76.7\% and 26.7\% for Ross and ISA Label, respectively.
\end{abstract}

Keywords: broiler, Salmonella Enteritidis, infection, egg shell, albumen, vertical infection

Recebido em 2 de maio de 2007

Aceito em 29 de agosto de 2008

*Autor para correspondência (corresponding author)

E-mail: henrique@vet.ufg.br 


\section{INTRODUÇÃO}

$\mathrm{Na}$ fase inicial de desenvolvimento, um ovo fertilizado contém o embrião, que é protegido pela casca, a principal linha de defesa do blastoderme contra o desafio do meio ambiente (Gonzales e Café, 2003).

Os ovos podem se contaminar com Salmonella como resultado da infecção do tecido reprodutivo da galinha durante a formação do folículo da gema e do albúmen no oviduto, antes da formação da casca, resultando em transmissão vertical. Os ovos também se contaminam após a formação da casca, durante sua passagem pela cloaca, ou pelo contato com: fezes, material da cama ou do piso, forro do ninho, mãos do tratador, água, bandejas, ou qualquer local contaminado no incubatório ou granja, caracterizando a transmissão horizontal (Miyamoto et al., 1997; Cox et al., 2000; Gustin, 2003; Patricio, 2003).

O ovo é um meio propício para desenvolvimento de microrganismos, porém possui barreiras intrínsecas de defesa contra sua multiplicação. A cutícula formada pela camada delgada de glicoproteína reveste a casca e protege $99 \%$ dos poros, por um curto período. A penetração de bactérias é limitada, ainda, pela barreira física da casca e suas membranas, que servem como filtros, e pelo albúmen, que possui mecanismos químicos e físicos que impedem a multiplicação e o deslocamento bacteriano (Board e Tranter, 1986; Morris, 1990). Essa proteção é importante, pois um único ovo contaminado com Salmonella na incubadora pode disseminar a bactéria no ambiente (Bayle et al., 1998). Todas as fontes potenciais de contaminação são relevantes, mas o ovo fértil é crítico na cadeia de produção (Leitão, 2001).

Porosidade, qualidade da cutícula, espessura da casca, rachadura e trincas favorecem a penetração bacteriana no ovo (Soncini e Bittencourt, 2003). No entanto, a penetração pode ocorrer em ovos íntegros antes do estabelecimento cuticular protéico. A contaminação externa da casca de ovos íntegros pode resultar no estabelecimento da infecção durante a incubação (Board, 1968).

O manuseio de ovos comerciais pode propiciar um alto nível de contaminação com Salmonella
Enteritidis, e, provavelmente, o embandejamento manual dos ovos seja um ponto de recontaminação (Henzler et al., 1999).

Os objetivos deste estudo foram avaliar a capacidade de penetração da SEpt4 inoculada na casca e no albúmen, bem como sua habilidade de migrar para outros componentes dos ovos e determinar mortalidade embrionária e assim infectar o trato gastrintestinal dos pintos ao nascimento de duas linhagens de frango de corte.

\section{MATERIAL E MÉTODOS}

Realizaram-se dois experimentos. No experimento 1, foram utilizados 200 ovos incubáveis da linhagem Ross e, no experimento 2, 194 ovos incubáveis da linhagem ISA Label, obtidos de matrizes de 42 e 36 semanas de idade, respectivamente. Os ovos foram provenientes de duas granjas localizadas na região Centro-Oeste, onde rotineiramente se realiza o controle de Salmonella sp., por meio de análise de resíduos de incubação.

Os ovos, transportados ao laboratório imediatamente após a colheita, foram pesados, identificados, distribuídos em quatro tratamentos e mantidos à temperatura ambiente por $18 \mathrm{~h}$. Os tratamentos, dentro de cada experimento, foram: tratamento 1 (T1) - constituído de 50 ovos da linhagem Ross ou 48 da ISA Label, inoculados com $0,1 \mathrm{ml}$ de solução salina a $0,85 \%$ tamponada (SSE) - placebo, na casca, formando o grupocontrole; tratamento 2 (T2) - composto de 50 ovos da linhagem Ross e 48 da ISA Label, inoculados na casca com $0,1 \mathrm{ml}$ SSE, contendo $1,5 \times 10^{2}$ unidades formadoras de colônias (UFC)/ml de SEpt4; tratamento 3 (T3) constituído de 50 ovos da linhagem Ross e 48 da ISA Label, inoculados no albúmen com $0,1 \mathrm{ml}$ do placebo; tratamento 4 (T4) - constituído de 50 ovos da linhagem Ross e 48 da ISA Label, inoculados no albúmen com $0,1 \mathrm{ml}$ de SSE contendo $1,5 \times 10^{2} \mathrm{UFC} / \mathrm{ml}$ de SEpt4.

O inóculo, cedido por Nunes (1999), foi preparado com SEpt4 isolada de amostras de frango de corte; a concentração foi $1,5 \mathrm{x}$ 102UFC/ml de SEpt4, conforme descrito por Bradshaw et al.(1990).

Para a obtenção do inóculo, a estirpe foi repicada em ágar verde brilhante e incubada a $37^{\circ} \mathrm{C}$ por 
18-20h. Em seguida, as células foram suspensas em SSE e mantidas a $40^{\circ} \mathrm{C}$; a concentração foi de 1,5 x 102UFC/ml, ajustada com auxílio da escala de MacFarland (Fernández et al., 2001). A concentração foi confirmada pelo plaqueamento das diluições decimais seriadas em ágar verde brilhante, com posterior incubação a $37^{0} \mathrm{C}$ por 18-20h e contagem das UFC.

Os procedimentos de inoculação foram realizados com material esterilizado e em câmara asséptica com grau de segurança II. Os ovos foram expostos ao inóculo de SEpt4, simulando possível contaminação da casca no embandejamento (T2) por contato com as mãos revestidas com luvas descartáveis, umedecidas com $0,1 \mathrm{ml}$ de SSE contendo $1,5 \times 10^{2} \mathrm{UFC} / \mathrm{ml}$ de SEpt4. Para tal, depositou-se o inóculo com seringas e agulhas de tuberculina nas mãos revestidas com luvas. Cada ovo foi mantido por 20 segundos nas mãos contaminadas, sendo a superfície do ovo totalmente molhada pela solução. O mesmo procedimento foi realizado empregando-se o placebo (T1).

A inoculação no albúmen, simulando a infecção do oviduto (T4) foi realizada após perfuração com furadeira com uma broca de calibre $1,5 \mathrm{~mm}$ na região da câmara de ar, usando seringas de tuberculina contendo $0,1 \mathrm{ml}$ de SSE $1,5 \mathrm{x}$ $10^{2} \mathrm{UFC} / \mathrm{ml}$ de SEpt4. A agulha, de calibre $12,7 \mathrm{x}$ $0,33 \mathrm{~mm}$, foi introduzida na câmera de ar, e o conteúdo depositado no albúmen, em um ângulo aproximado de $30^{\circ}$. Em seqüência, os orifícios foram vedados com parafina. Os ovos do T3 foram submetidos aos mesmos procedimentos empregando-se o placebo.

Os ovos foram encaminhados, imediatamente, para as incubadoras de viragem automática a cada quatro horas; a temperatura foi ajustada para $37,5^{\circ} \mathrm{C}$ e umidade relativa de $60 \%$.

Às 24h, 96h, 438h e 528h de incubação, foram colhidos dois ovos para pesquisa de Salmonella Enteritidis (SE) na casca, nas membranas da casca, na gema/saco da gema, assim como nos albúmens/líquidos da cavidade alantóide e nos embriões, a partir de 15 dias de idade. A casca foi cuidadosamente quebrada com tesouras e pinças esterilizadas, e os fragmentos da casca e de suas membranas foram colocados, separadamente, em outras placas para pesagem e processamento bacteriológico. O conteúdo foi vertido em outras placas de Petri, possibilitando que o albúmen, o saco da gema e os embriões, se presentes, se mantivessem separados. Pesaram-se $0,5 \mathrm{~g}$ de cada amostra em balança de precisão de $0,001 \mathrm{~g}$, os quais foram processadas bacteriologicamente de acordo com o GPL (Monitoring..., 1997).

Com 96h e 438h de incubação, cada ovo foi examinado ao ovoscópio. Os ovos que não apresentaram embriões viáveis foram retirados do processo e analisados quanto ao período de mortalidade embrionária. Aos 19 dias de incubação, os ovos foram colocados em embalagens individuais com o objetivo de obter o peso de cada pinto em relação ao ovo.

Para o embriodiagnóstico, as cascas foram quebradas, e os conteúdos vertidos em uma placa de Petri e analisados. Foram classificados como inférteis os ovos com pontos brancos; os férteis com mortalidade precoce - mortos até quatro dias; os férteis com mortalidade intermediária - mortos de cinco até 18 dias; e os férteis com mortalidade tardia - mortos de 19 a 22 dias de incubação. Ao final do período de incubação, avaliaram-se a eclodibilidade de ovos férteis (\%), a eclodibilidade total $(\%)$ e a fertilidade $(\%)$.

Após a eclosão, pesaram-se os pintos e colheu-se o mecônio por swab cloacal ou por compressão na região dorsoventral da cloaca. A recuperação de Salmonella nessas amostras foi realizada segundo a metodologia descrita em Métodos... (1999).

Os isolados das amostras dos ovos e mecônios que apresentaram reações bioquímicas compatíveis com Salmonella foram submetidos aos testes sorológicos com soro polivalente anti-O de Salmonella; se positivos à sorologia, foram remetidos à Fundação Osvaldo Cruz para confirmação do sorovar isolado.

$\mathrm{O}$ teste não paramétrico do qui-quadrado foi empregado para avaliar a freqüência da mortalidade embrionária e o rendimento de incubação e de pintos nascidos infectados (Sampaio, 1998).

\section{RESULTADOS}

$\mathrm{Na}$ inoculação via casca não houve diferença $(\mathrm{P}>0,05)$ entre os tratamentos tanto da Ross quanto da ISA Label (Tab. 1). A inoculação no albúmen com SEpt4 resultou em menor eclodibilidade total e dos ovos férteis $(\mathrm{P}<0,05)$ em relação à inoculação via casca e placebo para as duas linhagens estudadas. 
Tabela 1. Rendimento da incubação de ovos oriundos de matrizes das linhagens Ross e ISA Label inoculados com Salmonella Enteritidis fagotipo 4 na casca ou no albúmen

\begin{tabular}{|c|c|c|c|c|c|c|c|c|}
\hline \multirow{3}{*}{ Rendimento } & \multicolumn{4}{|c|}{ Ross (Exp. 1) } & \multicolumn{4}{|c|}{ ISA Label (Exp. 2) } \\
\hline & \multicolumn{2}{|c|}{ Casca } & \multicolumn{2}{|c|}{ Albúmen } & \multicolumn{2}{|c|}{ Casca } & \multicolumn{2}{|c|}{ Albúmen } \\
\hline & $\mathrm{T} 1$ & $\mathrm{~T} 2$ & T3 & $\mathrm{T} 4$ & T1 & $\mathrm{T} 2$ & $\mathrm{~T} 3$ & $\mathrm{~T} 4$ \\
\hline Fertilidade & 98,0 & 100,0 & 96,0 & 98,0 & 98,0 & 100,0 & 96,0 & 98,0 \\
\hline Eclodibil & $85,7 \mathrm{a}$ & $83,4 \mathrm{a}$ & $84,7 \mathrm{a}$ & $68,3 \mathrm{~b}$ & $89,4 \mathrm{a}$ & $83,3 \mathrm{a}$ & $84,7 \mathrm{a}$ & $68,0 \mathrm{~b}$ \\
\hline Eclodibilidade/total & $84,5 \mathrm{a}$ & $80,0 \mathrm{a}$ & $78,2 \mathrm{a}$ & $64,0 \mathrm{~b}$ & $84,4 \mathrm{a}$ & $80,0 \mathrm{a}$ & $78,2 \mathrm{a}$ & $64,0 \mathrm{~b}$ \\
\hline
\end{tabular}

T1: placebo; T2: inoculado na casca com SEpt4; T3: placebo; T4: inoculado no albúmen com SEpt4.

Letras diferentes na mesma linha indicam diferença $(\mathrm{P}<0,05)$ entre os valores.

Em T4 as taxas de mortalidade tardia e acumulada, tanto para Ross como ISA Label, foram maiores $(\mathrm{P}<0,05)$ em relação a dos demais tratamentos (Tab. 2). As taxas de mortalidade precoce e intermediária não diferiram entre si $(\mathrm{P}>0,05)$.

$\mathrm{Na}$ inoculação na casca, que simulou a transmissão horizontal, a maioria das amostras analisadas foi positiva para Salmonella Enteritidis, mostrando que essa se manteve viável e disseminou para todas as estruturas do ovo desde o início da incubação. Salmonella Enteritidis manteve-se viável em $87,5 \%$ e $62,5 \%$ das cascas e membranas da Ross e ISA Label, respectivamente (Tab. 3).

No final do processo de incubação, ocorreu a migração do patógeno das cascas e membranas para a cavidade alantóide em $37,5 \%$ e $25,0 \%$ (438/528h) e para o saco vitelínico em $12,5 \%$ e $12,5 \%$ (528h) dos embriões das linhagens Ross e ISA Label, respectivamente.

Tabela 2. Freqüência (\%) de mortalidade embrionária de ovos oriundos de matrizes das linhagens Ross e ISA Label inoculados ou não com Salmonella Enteritidis fagotipo 4 na casca e no albúmen

\begin{tabular}{|c|c|c|c|c|c|c|c|c|}
\hline \multirow{3}{*}{ Mortalidade } & \multicolumn{4}{|c|}{ Ross (Exp. 1) } & \multicolumn{4}{|c|}{ ISA Label (Exp. 2) } \\
\hline & \multicolumn{2}{|c|}{ Casca } & \multicolumn{2}{|c|}{ Albúmen } & \multicolumn{2}{|c|}{ Casca } & \multicolumn{2}{|c|}{ Albúmen } \\
\hline & T1 & $\mathrm{T} 2$ & T3 & T4 & $\mathrm{T} 1$ & $\mathrm{~T} 2$ & T3 & $\mathrm{T} 4$ \\
\hline Precoce & 2,2 & 4,3 & 2,2 & 2,1 & 0,0 & 2,2 & 2,2 & 2,2 \\
\hline Intermediária & 4,2 & 6,2 & 4,2 & 12,8 & 4,4 & 6,7 & 4,5 & 8,7 \\
\hline Tardia & $4,2 \mathrm{a}$ & $6,2 \mathrm{a}$ & $8,5 \mathrm{a}$ & $17,0 \mathrm{~b}$ & $2,2 \mathrm{a}$ & $4,5 \mathrm{a}$ & $8,9 a$ & $13,0 \mathrm{~b}$ \\
\hline Acumulada & $10,6 a$ & $16,7 \mathrm{a}$ & $14,9 a$ & $31,9 b$ & $6,6 \mathrm{a}$ & $13,4 a$ & $15,6 a$ & $23,9 b$ \\
\hline
\end{tabular}

Letras diferentes na mesma linha indicam diferença $(\mathrm{P}<0,05)$ entre os valores.

T1: placebo; T2: inoculado na casca com SEpt4; T3: placebo; T4: inoculado no albúmen com SEpt4.

Tabela 3. Freqüência de isolamentos de Salmonella Enteritidis nas estruturas de ovos férteis oriundos de matrizes das linhagens Ross e ISA Label inoculados ou não com Salmonella Enteritidis fagotipo 4 na casca e no albúmen

\begin{tabular}{|c|c|c|c|c|c|c|c|c|}
\hline \multirow{3}{*}{ Estrutura do ovo } & \multicolumn{4}{|c|}{ Ross (Exp. 1) } & \multicolumn{4}{|c|}{ ISA Label (Exp. 2) } \\
\hline & \multicolumn{2}{|c|}{ Casca } & \multicolumn{2}{|c|}{ Albúmen } & \multicolumn{2}{|c|}{ Casca } & \multicolumn{2}{|c|}{ Albúmen } \\
\hline & $\mathrm{T} 1$ & $\mathrm{~T} 2$ & T3 & $\mathrm{T} 4$ & $\mathrm{~T} 1$ & $\mathrm{~T} 2$ & T3 & T4 \\
\hline Cascas/membranas & 0,0 & 87,5 & 0,0 & 87,5 & 0,0 & 62,5 & 0,0 & 62,5 \\
\hline Liquido alantóide & 0,0 & $37,5 \mathrm{a}$ & 0,0 & $87,5 b$ & 0,0 & $25,0 \mathrm{a}$ & 0,0 & $87,5 b$ \\
\hline Saco vitelínico & 0,0 & $12,5 \mathrm{a}$ & 0,0 & $87,5 b$ & 0,0 & $12,5 \mathrm{a}$ & 0,0 & $87,5 b$ \\
\hline Embriões & 0,0 & 50,0 & 0,0 & 100,0 & 0,0 & 0,0 & 0,0 & 50,0 \\
\hline
\end{tabular}

Letras diferentes na linha indicam diferença $(\mathrm{P}<0,05)$ entre os valores.

T1: placebo; T2: inoculado na casca com SEpt4; T3: placebo; T4: inoculado no albúmen com SEpt4. 
Houve diferença na freqüência de isolamentos do agente infeccioso entre inoculação na casca e no albúmen. Pelo albúmen houve $(\mathrm{P}<0,05)$ mais facilidade de superar as defesas do ovo que pela casca.

A relação ovo/pinto (Tab. 4) situa-se entre $65,7 \%$ e 72,5\%, identificando menor relação de inoculados no albúmen e com Salmonella
Enteritidis, porém não houve diferença entre os valores $(\mathrm{P}>0,05)$.

O mecônio dos pintos oriundos de ovos inoculados com Salmonella Enteritidis na casca, apresentou diferença $(\mathrm{P}<0,05)$ quanto a colonização intestinal em relação ao mecônio de pintos nascidos de ovos inoculados no albúmen da linhagem Ross (Tab. 5).

Tabela 4. Relação peso médio do ovo / peso médio do pinto das linhagens Ross e ISA Label inoculados ou não com Salmonella Enteritidis fagotipo 4 na casca e no albúmen

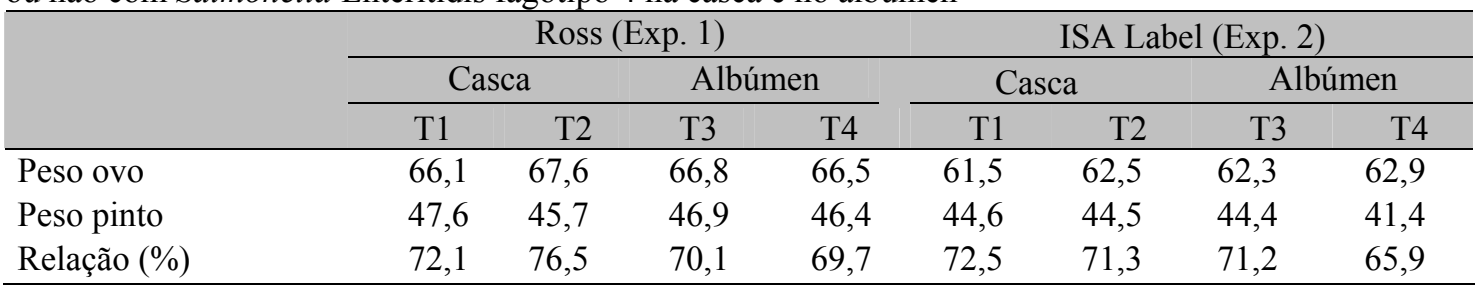

T1: placebo; T2: inoculado na casca com SEpt4; T3: placebo; T4: inoculado no albúmen com SEpt4.

$\mathrm{Na}$ linhagem Ross, no mecônio dos pintos nascidos de ovos inoculados com Salmonella Enteritidis no albúmen, o número de isolamentos foi mais alto $(\mathrm{P}<0,05)$ em relação ao de isolamentos de pintos nascidos de ovos inoculados na casca. Essas diferenças também ocorreram na linhagem ISA Label, mas em menor proporção (Tab. 5).

Tabela 5. Bacteriologia dos suabes de mecônio obtidos $15 \mathrm{~h}$ pós a eclosão de pintos das linhagens Ross e ISA Label experimentalmente inoculados ou não com Salmonella Enteritidis fagotipo 4 na casca e no albúmen

\begin{tabular}{|c|c|c|c|c|c|c|c|c|}
\hline & \multicolumn{4}{|c|}{ Ross (Exp. 1) } & \multicolumn{4}{|c|}{ ISA Label (Exp. 2) } \\
\hline & \multicolumn{2}{|c|}{ Casca } & \multicolumn{2}{|c|}{ Albúmen } & \multicolumn{2}{|c|}{ Casca } & \multicolumn{2}{|c|}{ Albúmen } \\
\hline & $\mathrm{T} 1$ & $\mathrm{~T} 2$ & T3 & $\mathrm{T} 4$ & $\mathrm{~T} 1$ & $\mathrm{~T} 2$ & T3 & $\mathrm{T} 4$ \\
\hline & $0 / 30(0))$ & $\begin{array}{c}15 / 30 \\
(50 \%) a\end{array}$ & $0 / 30$ & $\begin{array}{c}23 / 30 \\
(76,7) b\end{array}$ & $0 / 30(0)$ & $\begin{array}{c}3 / 30 \\
(10 \%) a\end{array}$ & $0 / 30$ & $\begin{array}{r}8 / 30 \\
(26,7) \mathrm{b}\end{array}$ \\
\hline Positivo/total & $\begin{array}{c}\mathrm{T} 1+\mathrm{T} 3 \\
0 / 60\end{array}$ & & $\begin{array}{c}\mathrm{T} 2+\mathrm{T} 4 \\
38 / 60 \\
(63,3 \%)\end{array}$ & & $\begin{array}{c}\mathrm{T} 1+\mathrm{T} 3 \\
0 / 60\end{array}$ & & $\begin{array}{c}\mathrm{T} 2+\mathrm{T} 4 \\
11 / 60 \\
(18,3 \%)\end{array}$ & \\
\hline
\end{tabular}

Letras diferentes na linha indicam diferença $(\mathrm{P}<0,05)$ entre os valores.

T1: placebo; T2: inoculado na casca com SEpt4; T3: placebo; T4: inoculado no albúmen com SEpt4.

Ovos inoculados com Salmonella Enteritidis na casca originaram $50,0 \%$ e $10,0 \%$, de pintos Ross e ISA Label, respectivamente, com colonização intestinal positiva $(\mathrm{P}<0,05)$. Nos inoculados no albúmen, observaram-se $76,7 \%$ e $26,7 \%$ de mecônio positivo nas linhagens Ross e ISA Label, respectivamente. As freqüências de isolamentos positivos entre pintos oriundos de ovos inoculados na casca e albúmen foram diferentes $(\mathrm{P}<0,05)$.

\section{DISCUSSÃO}

O pinto ao nascer representa 65 a $72 \%$ do peso do ovo (Patrício, 2003). Neste sentido, embora os ovos tenham sido inoculados na casca e no albúmen antes de serem incubados, os dados estão de acordo com as condições normais do processo de incubação artificial, sugerindo que a inoculação não interferiu na relação ovo/pinto. 
A produção de pintos saudáveis é um dos principais objetivos dos incubatórios. No presente ensaio, os ovos apresentaram índice de fertilidade acima de 95\% em todos os tratamentos e linhagens. Dentre os parâmetros de incubação avaliados, a fertilidade é um dos mais importantes, sendo aceitável uma taxa de $90 \%$ de fertilidade (Heir e Jarp, 2001).

O fato de as eclodibilidades total e de ovos férteis inoculados na casca não terem sido afetadas por Salmonella Enteritidis confirma resultados de experimentos anteriores, que também não indicaram efeito de Salmonella Typhimurium (Cason et al., 1994) e Salmonella Enteritidis (Lister, 1988) sobre os índices de incubação. A bactéria, quando inoculada na casca, permaneceu na sua superfície por até $528 \mathrm{~h}$ e invadiu as membranas da casca. No entanto, poucas amostras colonizaram o saco vitelínico, o líquido alantóide e, ainda, poucos embriões foram positivos para Salmonella Enteritidis.

Soncini e Bittencourt (2003) relataram que a maior porosidade, a menor qualidade da cutícula, a menor espessura da casca e a presença de rachaduras e trincas favorecem a penetração bacteriana no ovo. Hutchison et al. (2003) apontaram que a sobrevivência das bactérias na superfície da casca pode estar relacionada às condições físicas da cutícula e à integridade da casca, à presença de água na casca, à concentração de ferro na água que entra em contato com o ovo e à presença de material orgânico. Messens et al. (2005), em artigo de revisão, relataram que existem fatores extrínsecos e intrínsecos que podem afetar a penetração de Salmonella. Dentre os extrínsecos, destacaram a cepa e a concentração de bactérias, a temperatura, a umidade e a presença de matéria orgânica. Em relação aos intrínsecos citaram a cutícula, as características da casca - integridade, espessura, porosidade e defeitos $-\mathrm{e}$ as propriedades das membranas.

Os mecanismos de defesa dos ovos foram superados em poucas amostras quando a via de inoculação foi a casca. As membranas internas da casca, compostas de queratina e de fibras de mucina com albúmen nos interstícios, agem como filtros de microrganismos. A ligação entre as membranas é descrita como tênue e com falhas, está disposta de forma irregular e apresenta espaços entre elas. Isso pode facilitar a permanência de bactérias que, pelo acesso à água, podem se reproduzir e destruir a função das membranas, principalmente quando se tem um inóculo bacteriano e os ovos são mantidos a $37^{\circ} \mathrm{C}$ (Nascimento e Salle, 2003).

Cason et al. (1993) observaram que, imediatamente após a inoculação de Salmonella, $100 \%$ das amostras da casca e membranas foram positivas para o patógeno. Após 17 e 21 dias de incubação, ocorreu redução de positividade para $38 \%$, o que levou à suspeita de que a bactéria morreu ou o número reduziu-se a ponto de não ser detectada. Segundo os autores, o ambiente da casca e membranas pode ser hostil ao desenvolvimento bacteriano, dado que em $62 \%$ das amostras o patógeno desapareceu, mas, ao mesmo tempo, pode ser favorável ao desenvolvimento, uma vez que alguns ovos proporcionaram contagem acima de $10^{6}$ UFC de Salmonella Typhimurium.

A eclodibilidade total e dos ovos férteis foi afetada quando se simulou a infecção do oviduto pela inoculação no albúmen. Ao final da incubação, Salmonella Enteritidis propiciou aumento da mortalidade embrionária nas duas linhagens, o que resultou naturalmente em menores taxas de eclodibilidade de ovos férteis, $68,0 \%$ e $67,4 \%$, e de ovos totais, $64,0 \%$ e $65,7 \%$ para as linhagens Ross e ISA Label, respectivamente. $\mathrm{Na}$ inoculação de Salmonella Enteritidis no albúmen, provavelmente ocorreu inibição do desenvolvimento e mortalidade bacteriana pelas substâncias antibacterianas presentes no ovo, as lisozimas $\mathrm{e}$ as ovotransferrinas. Ao final da incubação, as bactérias entraram em fase log, o que determinou mortalidade de $17,0 \%$ e $13,0 \%$ para as linhagens Ross e ISA Label, respectivamente. Portanto o rendimento de incubação foi influenciado pela inoculação de Salmonella Enteritidis no albúmen.

Há de se considerar que a bactéria foi depositada no albúmen no início da incubação, e este componente apresenta baixo teor de ferro, suficiente para permitir o desenvolvimento de quatro gerações de Salmonella Enteritidis a $25^{\circ} \mathrm{C}$ (Clay e Board, 1991). Quando a reserva de ferro se esgota, a bactéria entra na fase lag (Humphrey, 1994) e, por alguma razão, nas últimas horas de incubação entrou em fase log. 
Em relação à migração de Salmonella Enteritidis, ovos inoculados no albúmen apresentaram diferenças $(\mathrm{P}<0,05)$ quando comparados àqueles inoculados na casca. Nesta via, o patógeno migrou para os componentes dos ovos na maioria das repetições desde o início da incubação. Há diferentes opiniões a respeito da presença da bactéria no interior do ovo. Muliari e Zavanella (1994) relataram que o albúmen não é um substrato apropriado para o desenvolvimento de Salmonella Enteritidis, o que foi confirmado por Oliveira e Silva (2000). A bactéria, ao penetrar no ovo e atingir o albúmen, pode se multiplicar por curto período de tempo e, de forma rápida, ser reduzida numericamente, pois os componentes do albúmen e o $\mathrm{pH}$ são desfavoráveis ao seu desenvolvimento (Board, 1968).

Constatou-se diferença $(\mathrm{P}<0,05)$ entre as freqüências de pintos positivos para o patógeno inoculados na casca em relação aos inoculados no albúmen ao avaliar-se o número de pintos infectados. Os mecanismos de defesa dos ovos foram efetivos na maioria das amostras quando a via de inoculação foi a casca. A bactéria permaneceu na superfície e invadiu as membranas da casca na maioria das amostras até $528 \mathrm{~h}$ de incubação, no entanto em poucas amostras foram atingidos o saco vitelínico, o líquido alantóide, os embriões e os pintos. Cason et al. (1993) comprovaram que muitas aves adquirem Salmonella de suas próprias cascas e membranas ao nascimento. Os dados obtidos no presente trabalho e referentes aos componentes dos ovos e mecônio, 15h após eclosão, confirmaram os resultados obtidos por aqueles autores.

Isso indica que a infecção evoluiu em tempos diferentes. No caso dos ovos inoculados na casca, provavelmente ocorreu a infecção no período final de incubação e durante a eclosão, dados que concordam parcialmente com Cason et al. (1993) e Bayle et al. (1998). No caso dos ovos inoculados no albúmen, a infecção ocorreu durante a incubação. De acordo com Boleli (2003), por menor que seja o número de ovos contaminados nos nascedouros, a sobrevivência de bactérias patogênicas, como salmonelas, pode causar infecção das aves recém-eclodidas no processo de incubação.
Conclui-se que houve colonização intestinal em pintos oriundos da inoculação experimental na casca e no albúmen, com maior colonização intestinal $15 \mathrm{~h}$ pós-eclosão, simulando transmissão vertical.

\section{REFERÊNCIAS BIBLIOGRÁFICAS}

BAYLE, J.S.; CASON, J.A.; COX, N.A. Effect of Salmonella in young chicks on competitive treatment. Poult. Sci., v. 77, p.394-399, 1998.

BOARD, R.G. Egg quality: a study of the hens's eggs. Edinburg: Oliver and Boyd, 1968. p.133.

BOARD, R.G.; TRANTER, H.S. The microbiology of eggs. In: STADELMAN,W.J.; COTTERILL,O.J. (Eds). Egg science and technology. 3.ed. Edinburg: Oliver and Boyd. 1986, p.75-96.

BOLELI, I.C. Estresse, mortalidade e malformações embrionárias. In: MACARI. M.; GONZALES, E. Manejo da incubação. Campinas: FACTA, 2003. p.394-434.

BRADSHAW, J.G.; SHAH, D.B.; FORNEY, E. et al. Growth of Salmonella Enteritidis in shell eggs from normal and seropositive hens. J. Food Prot., v.53, p.651-669, 1990.

CASON, J.A.; BAILEY, J.S.; COX, N.A. Location of Salmonella typhimurium during incubation and hatching of inoculated eggs. Poult. Sci., v.72, p.2064-2068, 1993.

CASON, J.A.; COX, N.A.; BAILEY, J.S. Transmission of Salmonella typhimurium during hatching of broiler chicks. Avian Dis., v.38, p.583-588, 1994.

CLAY, C.E.; BOARD, R.G. Growth of Salmonella Enteritidis in artificially contaminated hen's shell eggs. Epidemiol. Infect., v.106, p.271-281, 1991.

COX, N.A.; BERRANGE, M.E.; CASON, J.A. Salmonella penetration of eggs shells and proliferation in broiler hatching eggs. Poult. Sci., v.79, p.1571-1574, 2000.

FERNÁNDEZ, A.; LARA, C.; LOSTE, A. et al. Control of Salmonella Enteritidis phage type 4 experimental infection by fosfomycin in newly hatched chicks. Comp. Immunol. Microbiol. Infect. Dis., v.24, p.207-216, 2001. 
GONZALES, E.; CAFÉ, M.B. Produção de pintos com qualidade total. In: MACARI, M.; GONZALES, E. Manejo da incubação. Campinas: FACTA, 2003. p.515-526.

GUSTIN, P.C. Biossegurança no incubatório.In: MACARI, M.; GONZALES, E. Manejo da incubação. Campinas: FACTA, 2003. p.297-349.

HEIR, B.T.; JARP, J. An epidemiological study of the hatchability in broiler breeder flocks. Poult. Sci., v.80, p.1132-1138, 2001.

HENZLER, D.J.; KRADEL, D.C.; SIRCHO, W.M. Management and environmental risk factors for Salmonella Enteritidis contamination of eggs. Am. J. Vet., v.59, p.824-7829, 1999.

HUMPREY, T.J. Contamination of eggshell and contents with Salmonella Enteritidis: a review. Int. J. Food Microbiol., v.21, p.31-40, 1994.

HUTCHISON, M.L.; GITTINS, J.; WALKER, A. et al. Washing table eggs: a review of the scientific and engineering issues. Poult. Sci. J., v.59, p.233-248, 2003.

LEITÃO, M.F. Qualidade e segurança alimentar em produtos avícolas. In: CONFERÊNCIA APINCO 2001 DE CIÊNCIAS E TECNOLOGIA AVÍCOLAS, 2001 Campinas. Anais...Campinas: FACTA, 2001. p.181-190.

LISTER, S.A. Salmonella Enteritidis infection in broilers and broiler breeders. Vet. Rec., v.123, p.350, 1988.

MESSENS, W.; GRIJSPEERDT, K.; HERMAN, L. Eggshell penetration by Salmonella: a review. World's Poult. Sci., v.61, p.71-85, 2005.

MÉTODOS de análises microbiológicas para alimentos. Brasília: Coordenação Nacional de Laboratório Animal - MAPA, 1999, 226p.

MIYAMOTO, T.; BABA, E.; TAKANA, T. et al. Salmonella Enteritidis contamination of eggs from hens inoculated by vaginal, cloacal, and intravenous routes. Avian Dis., v.41, p.296-303, 1997.

MONITORING and detection of Salmonella in poultry and poultry environments. Oakwood: Georgia Poultry Laboratory, 1997. 293p. [Workshop]

MORRIS, G.K. Salmonella enteritidis and eggs: assessment of risk. Dairy, Food Environ. Sanit., v.10, p.279-281, 1990.

MULIARI, R.; ZAVANELLA, M. Influence of temperature on Salmonella Enteritidis growth in hens' eggs componentes. Vet. Rec., v.134, p.583, 1994.

NASCIMENTO, V.P.; SALLE, C.P. O ovo. In: MACARI, M., GONZALES, E. (Eds). Manejo da incubação. Campinas: FACTA, 2003. p.3450 .

NUNES, I.A. Salmonella Enteritidis - fagotipos, susceptibilidade a drogas a antimicrobianas $e$ epidemiologia molecular baseada na sonda complementar ao rRNA. 1999. 119f. Tese (Doutorado) - Instituto de Ciências Biomédicas, Universidade de São Paulo, São Paulo.

OLIVEIRA, D.; SILVA, E.N. Salmonela em ovos comerciais: ocorrência, condições de armazenamento e desinfecção da casca. Arq. Bras. Med. Vet. Zootec., v.52, p.655-661, 2000.

PATRICIO, I.S. Manejo do ovo incubável da granja ao incubatório. In: MACARI. M.; GONZALES, E. (Eds). Manejo da Incubação. Campinas: FACTA, 2003. p.163-179.

SAMPAIO, I.B.M. Estatística aplicada à experimentação animal. Belo Horizonte: FEPMVZ, 1998. 221p.

SONCINI, R.A.; BITTENCOURT, F.L. Contaminação dos ovos após a postura. In: MACARI, M.; GONZALES, E. (Eds). Manejo da incubação. Campinas: FACTA, 2003. p.433453. 